\title{
DEVELOPMENT OF A MODEL FOR THE IMPROVEMENT OF SAFETY IN THE WORK PLACE THROUGH THE ANALYTIC NETWORK PROCESS
}

\author{
Fabio De Felice* \\ Department of Industrial Engineering \\ University of Cassino, Italy \\ E-mail: defelice@unicas.it \\ Antonella Petrillo \\ Department of Industrial Engineering \\ University of Cassino, Italy \\ E-mail: a.petrillo@unicas.it
}

\begin{abstract}
The aim of this study is to analyze the dynamics of cognitive processes by means of the technique of the ANP with the purpose to develop a method to improve safety in the workplace. Research has underlined how to minimize and improve safety in firms, it is not sufficient to reduce the "technological failures" but it is necessary to analyze the "human factor" therefore acting on aspects such as analysis of man-machine interfaces and decision support systems. Man is, therefore, the core of a cognitive process that leads to decisions, and therefore influences the safety of the whole system and of all operators according to his own reliability. The purpose of this study is the definition of a cognitive model based on the ANP through which we can "explain" the errors of a wrong decision-making process underlying incorrect performance and accidents at work. Through the ANP sources and typologies of hazard are identified in order to build the network decision-making and calculate the weights for each source of risk. The application of the method gives us, through the investigation of the decision-maker and its decisions, the definition of a "safety system". The implementation of the ANP allows us: to build a model that helps to measure and synthesize a large number of factors that must be considered in the complex decisions in industrial safety field; to reach the decision that better satisfies the multitude of objectives allowing to the decision-maker the synthesis of the large number of criteria or sub-criteria.
\end{abstract}

Keywords: ANP, Safety, Human factor, BBS, HRA

\section{Introduction}

Despite the reduction in number of accidents there are still several events that cause the death of many workers. $80 \%$ of industrial accidents is due to unsafe behavior, a poor structural condition or inadequate instrumentation technique. It is obvious that the accidental events can not be attributed only to chance. The only common denominator is, in fact, always the same, the lack of a structured system for prediction and control of behaviors related to work safety. Wherever you have an accident rate of less than one event every 2, 3 or 4 million hours worked, there are scientific methods of management of safe behavior, substantially similar in principles and application context, each different other only for details and arrangements related to the specificity of working or to the organizational structure.

The objective difficulties of governing the human factor and the human error, have made many experts believe that the conduct of preventive and safety were related to intrinsic characteristics of the person, as

${ }^{*}$ Corresponding author 
the traits of personality. Another explanation of the phenomenon credited accident is based, on the contrary, on the search for extrinsic causes, such as research productivity. In other words, the accident can be determined on one side by unsafe behavior and on the other, by structural conditions and inadequate instrumentation technique. From this point of view several methods have been developed to control the behavior of safety or methods for safety management based on better behavior critical to the safety of workers with the aim to drastically reduce accidents For risk analysis have been developed several techniques including: Safety Review, Checklist Analysis, Relative Ranking, What-if Analysis, Preliminary Hazard Analysis, Hazard and Operability (HAZOP), Failure Modes, Effects and Criticality Analysis (FMECA), Fault Tree Analysis (FTA), Event Tree Analysis (ETA), Cause-Consequence Analysis (CCA). In particular in our work we will analyse:

- The Behavior Based Safety (BBS), the only methodology for safety based on scientific principles of human behavior which allows to dramatically reduce the number of accidents at work;

- The Human Reliability Analysis (HRA), a recently spread method which focuses its attention on the responsibility of the "human factor".

It is evident that the inherent complexity of the study of human factors in the workplace safety requires the implementation of multi-criteria decision-making methods such as ANP. The aim of this work is to develop an algorithm that, starting from identification of possible sources of risk within the company and through the integration of BBS, HRA and ANP, enables Safety Planning. This analysis requires a detailed examination of work activities, which allows for the complete mapping of transactions and processes carried out in the workplace and identifies potential sources of risk for the health and safety of personnel. In the second place it is established, when performing a specific activity, the sources of risk and / or risk identified, involves real risk for the operator, taking into account the characteristics of working (modes of operation, characteristics of existing protective measures, etc..).

\section{Behavior Based Safety}

Increasing safety is often difficult, especially when you have already obtained good of results. The complacency, ie the high confidence in yourself and your ability is related to the loss of fear of injuring yourself which normally induce the workers to be careful. If the probability of accidents is high, confidence is not a problem: for example, it is quite rare to encounter difficulties in making welders wear protective devices because the probability of burning themselves, is so high as to continuously make them use their protective goggles. Most workers do not perceive accidents as possible and do not feel obliged to implement safety procedures. A constant level of excellence in safety requires the ability to manage much more than what most companies are able to achieve with traditional methods. Many accidents are the result of unsafe actions, rather than unsafe conditions, it follows that very few are the companies that manage to achieve a good level of compliance with their safety standards by adopting the methods currently in force. The effectiveness of a behavioral approach to safetys is demonstrated by a marked reduction of accidents. The Behavioral Based Safety is based on evidence that all the behaviors in the workplace (eg wear appropriate PPE) can be evoked by physical stimuli immediately prior (eg safety signs), but are strongly influenced by the immediate subsequent stimuli (eg comments by colleagues).

with BBS, we may:

- Identify, enumerate and classify the critical behavior - behavior that, if carried out in an unsafe manner, can lead to an accident ("behavioral inventory" or "pinpointing");

- Recognize the behavior in the workplace ("behavioral audit" or "bahavioral observation") in relation to the frequency of such acts;

- Identify the critical behavior to be addressed, the analysis of its causes in terms of antecedents and consequences ("behavior analisys") and to define corrective actions;

- Implement the corrective actions necessary to improve the behavior (and in particular new consequences).

The analysis of risk factors not only requires the analysis of tasks that people do but also how they are conducted, and that is why it was necessary to test stimuli before and consequent conduct. 


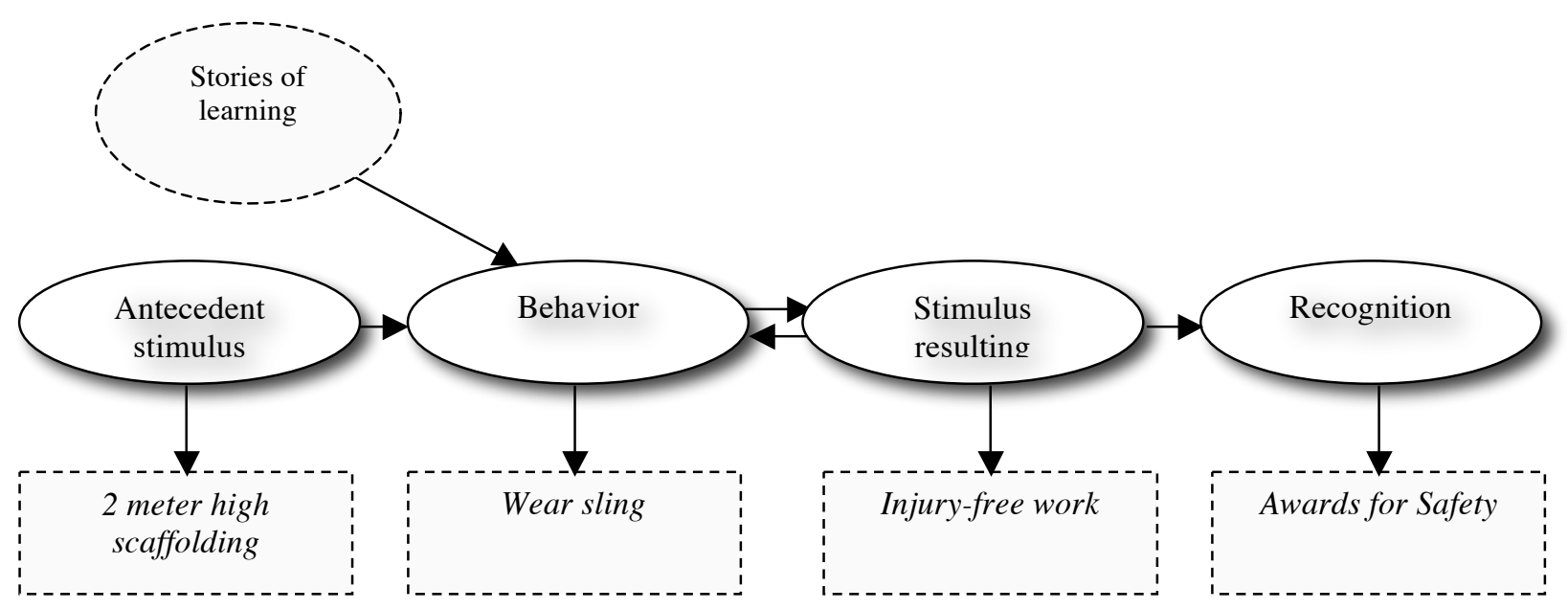

Figure 1. Scheme of behavioral analysis.

Furthermore, in order to develop a model that would create a safety culture, we considered that only through the identification of a Vision or a Mission, it is possible to make clear the ideal to be achieved, define the values, clarify to employees how to operate and establish a process to achieve the desired results. The analysis of behavior, obviously, has a particular importance in this model because it is the key element of both the processes and values.

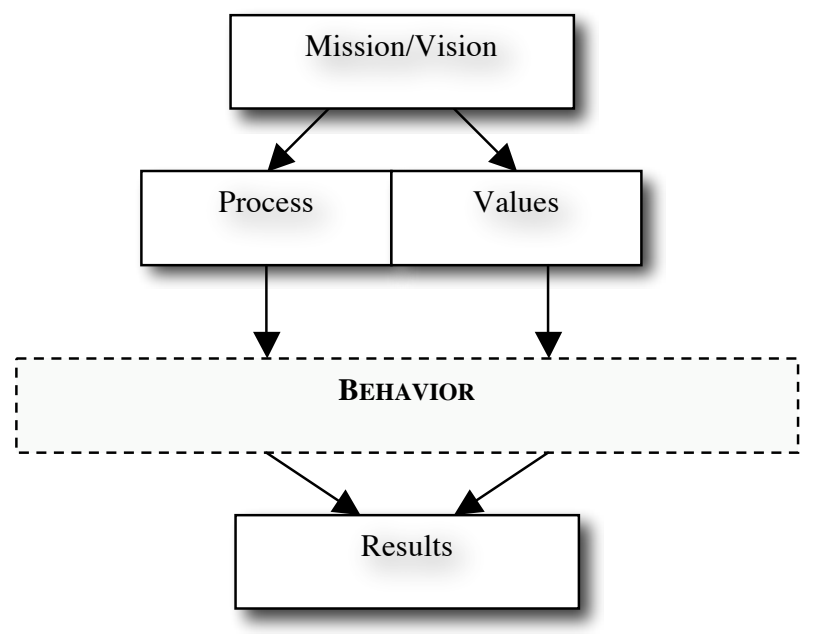

Figure 2. Elements of safety culture.

The key to the success of the process of safety based on behaviors is to establish groups that cooperate in the planning of the project. The application of the techniques has enabled us to:

- Develop plans for implementation of the process;

- Solve problems and improve the actions taken for safety;

- To analyze accidents in order to plan preventive measures.

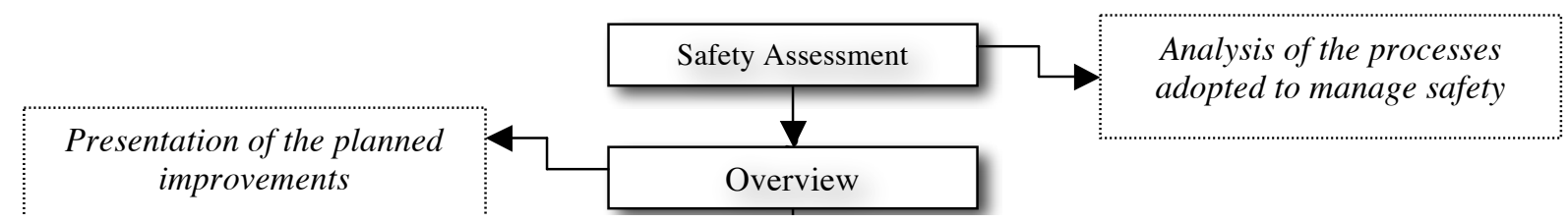


Figure 3. Safety Process.

Table 1. Groups involved in the construction of safety based on behaviors.

\begin{tabular}{|l|l|l|}
\hline \multicolumn{1}{|c|}{ Group } & \multicolumn{1}{|c|}{ Who participates } & \multicolumn{1}{c|}{ What produces } \\
\hline $\begin{array}{l}\text { Coordination Group. } \\
\text { The central committee } \\
\text { of health and safety. }\end{array}$ & Corporate Management. & $\begin{array}{l}\text { Constitutive act of the working group. } \\
\text { Approval of plans and definition of the project group. } \\
\text { Active participation in support of activities defined by } \\
\text { the project team. }\end{array}$ \\
\hline Project team. & $\begin{array}{l}\text { Representatives of workers. } \\
\text { Safety expert. } \\
\text { Technical Representative } \\
\text { Representative. management. }\end{array}$ & $\begin{array}{l}\text { Assessment of preliminary submission to management. } \\
\text { Drafting of guidelines, forms and materials for the } \\
\text { information/training. }\end{array}$ \\
\hline Executive Committee. & $\begin{array}{l}\text { Representatives of workers. } \\
\text { Safety expert. } \\
\text { Technical Representative. } \\
\text { Representative management. }\end{array}$ & $\begin{array}{l}\text { Conduct observations and publication of statistical } \\
\text { analysis of data collected. } \\
\text { Troubleshooting and ongoing maintenance of } \\
\text { behavioral safety. } \\
\text { Setting objectives for improvement. } \\
\text { Development and implementation of action plans. }\end{array}$ \\
\hline $\begin{array}{l}\text { Group of safety in the } \\
\text { workplace. }\end{array}$ & $\begin{array}{l}\text { Representatives of workers for } \\
\text { safety. }\end{array}$ & $\begin{array}{l}\text { Participation in the activities of observation. } \\
\text { Setting objectives for improvement. } \\
\text { Implementation of action plans appropriate to their } \\
\text { areas of expertise. }\end{array}$ \\
\hline
\end{tabular}




\section{The human factor: the prevention of risks and the HRA}

All the theories on safety and accident prevention work are based on a principle that provides for a mutual adaptation between three fundamental components of a system formed by man, machine and environment. The Human Reliability Analysis (HRA) has the aim of analyzing the human factor through two fundamental aspects:

- How to take into account this factor;

- The evaluation of the method adopted.

This type of analysis is closely linked both with purely engineering disciplines, such as the Probabilistic Safety Assessment (PSA), aimed at reducing the likelihood of accidental events and the minimization of the consequences through a process of propagation of disciplines like the psychological one which analyses human mental processes, such as Cognitive Science. The research based on HRA focuses on systems where the operator is essential to the functionality of the process and addresses many aspects of human-machine interface. The difficulties of analyzing the workplace stems from two factors:

- The logic of active-reactive, with the operator as an element capable of determining the state of the system;

- The dynamism of the system that is manifested in the ability of the system to assume different configurations in the same time space-time depending on the parameters of control and succession of events planned.

The research studies on the HRA also took into account:

- Analysis of the business where an episode that you did want not accurred, with research of the phenomena and the key issues that led to the result;

- The estimated probability of occurrence of accidents, with assessment of skill of the system to react to the award of the potential response.

In the development of the HRA proper analysis of human performance and the definition of error have a vital role, which can better be seen as:

- Due to an event;

- Incorrect process, implemented at the level of physical or intellectual;

- Accordingly, ie observable event.

From a technical-organizational point of view there are two types of errors:

- Errors that are active, associated with the performance of the operators more closely with complex systems (pilots, controllers, etc.).

- Latent errors that are committed by those who are far from allowing a direct control (the designers, manufacturers, support staff, etc.

Analyzing the human factor can reveal that humans can be divided into three distinct levels. The levels of performance in an integrated way contribute to human behavior and its cognitive activity:

- Level skill-based (SB): the control of behavior is automatic. The kind of behavior is mainly in preprogrammed routine (super-learned behaviors) with attention checks at specific points in the chain of behavior;

- Level rule-based (RB): This level happens with usual problems which solutions are governed by rules stored on the type if-then;

- Level knowledge-based (KB): This level of performance is used in the case of new situations for which actions must be planned "at the moment" using analytical processes.

The three performance levels are associated with three types of errors:

- The skill-based level is associated with a type of error known as slip or lapses, in which case the plan is formulated correctly, but the sequence of action is not executed as planned;

- The level-based and rule-based knowledge are mixed with a known type of error, respectively, under the name mistake RB and KB: in this case the sequence of action is executed as planned but the plan adopted was inappropriate for the achievement of objectives. 


\section{Model for improving safety in the workplace}

The complexity of the environment associated with the manifold features of the human factor as a result determines that all the reliability of the binomial man - the environment is practically governed by unpredictable variables whose accidents can never be eliminated entirely because both factors are not predictable. If, however, the two other risk factors, the technological and human one, are controlled and minimized, the accidental factor also appears likely to reduce concretely. In the context of risks considered, we saw that the sources of hazard can be basically of three types:

1. Technology;

2. Organization;

3. Human.

Only through the design of an appropriate system of safety can we ensure the reduction of damage due to one of the three sources listed above and therefore the improvement of safety at work.

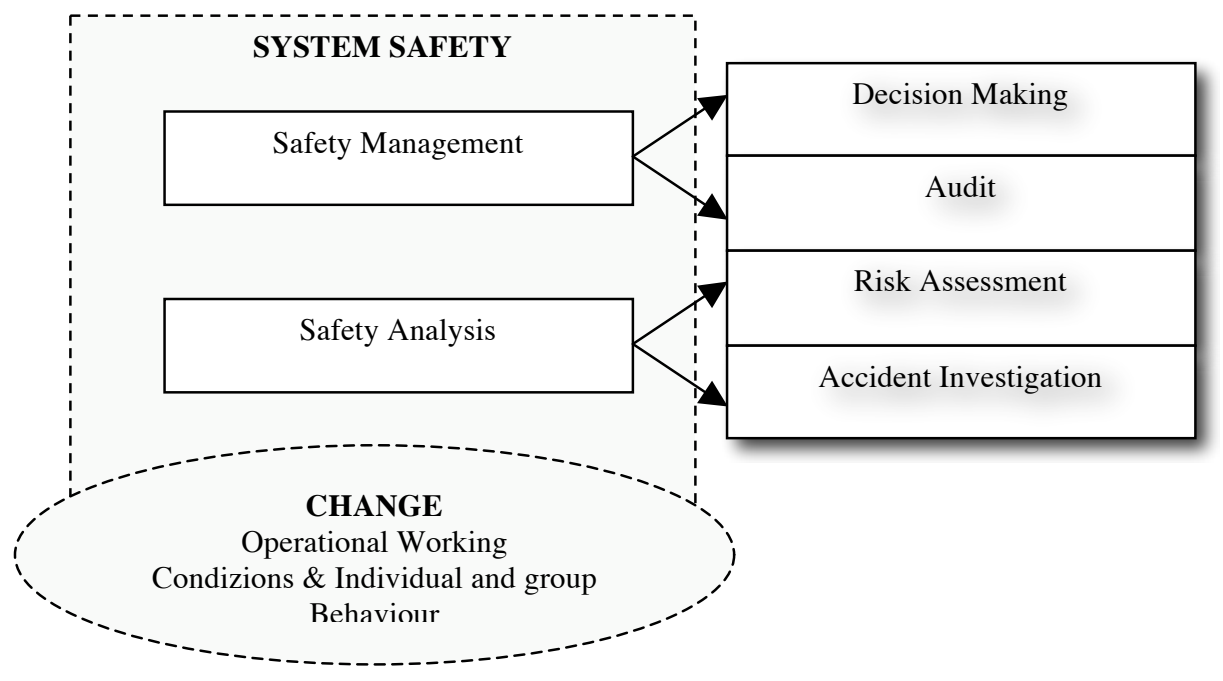

Figure 4. The safety system.

In developing our model we have identified two macro issues, which we believe necessary to consider the identification of the mental process that leads to error:

1. inclusion and "rigorous" human factors in the evaluations concerning hazards/damage;

2. identification of different types of erroneous actions ( "human error").

We implemented the model by following these logical steps:

1. analysis of the workplace;

2. identification of erroneous actions;

3. human reliability quantification;

4. development of a descriptive-numerical model based on ANP which allowed us to contemplate the human interactions in the logical structure of risk analysis techniques.

Below, in detail, the phases of the study that led to the development of the model in its entirety:

Step No 1: Breakdown of the workplace in the areas, processes or classes of persons. To proceed in a systematic way with hazard identification and planning of measures, we first split up the work environment in logical and understandable:

- Division into sectors / jobs (for example: workshop, production department, offices);

- Breakdown in work processes (eg storage, transport, packaging);

- Division into occupational groups or individuals (a job category including persons who perform the same activities, eg. Installers, and drivers who are exposed to common hazards). 
Step No 2: List of activities, work equipment and substances. For each work area, process or class of persons we have reported the following information:

- Activities (eg. sanding, sawing, etc.).

- Work equipment used (eg. circular saw for metal, portable ladders, pedestals)

- Substances used (eg. varnishes, detergents, acids) or releases of such substances (eg. vapors, dust, exhaust gases).

Step No 3: Identification of the hazards and stress factors. We identified the hazards and stress factors related to the activities, work equipment and substances previously listed. We used checklists, safety data sheets, manuals, etc.. to facilitate the identification of hazards and the planning of measures. At this stage it is necessary to conduct an inquiry on the workplace to "investigate" with the help of the workers the possible hazards they face every day, also those which seem less relevant.

Step No 4: Identification of actions that violate safety and adopt necessary measures to decrease human error.

At this point we can choose the most appropriate and determine whether:

- It is possible to remove the hazard by adopting a method of non-hazardous work or replace hazardous substances (eg. replace products containing solvents with others which do not);

- It is possible take technical measures (eg. parapets, screens, ventilation);

- It is possible take organizational measures (eg. changes to working time, training and education, varied activities, maintenance plans);

- It is possible take personal and behavioral measures (eg. use personal protective equipment conforming to safety standards).

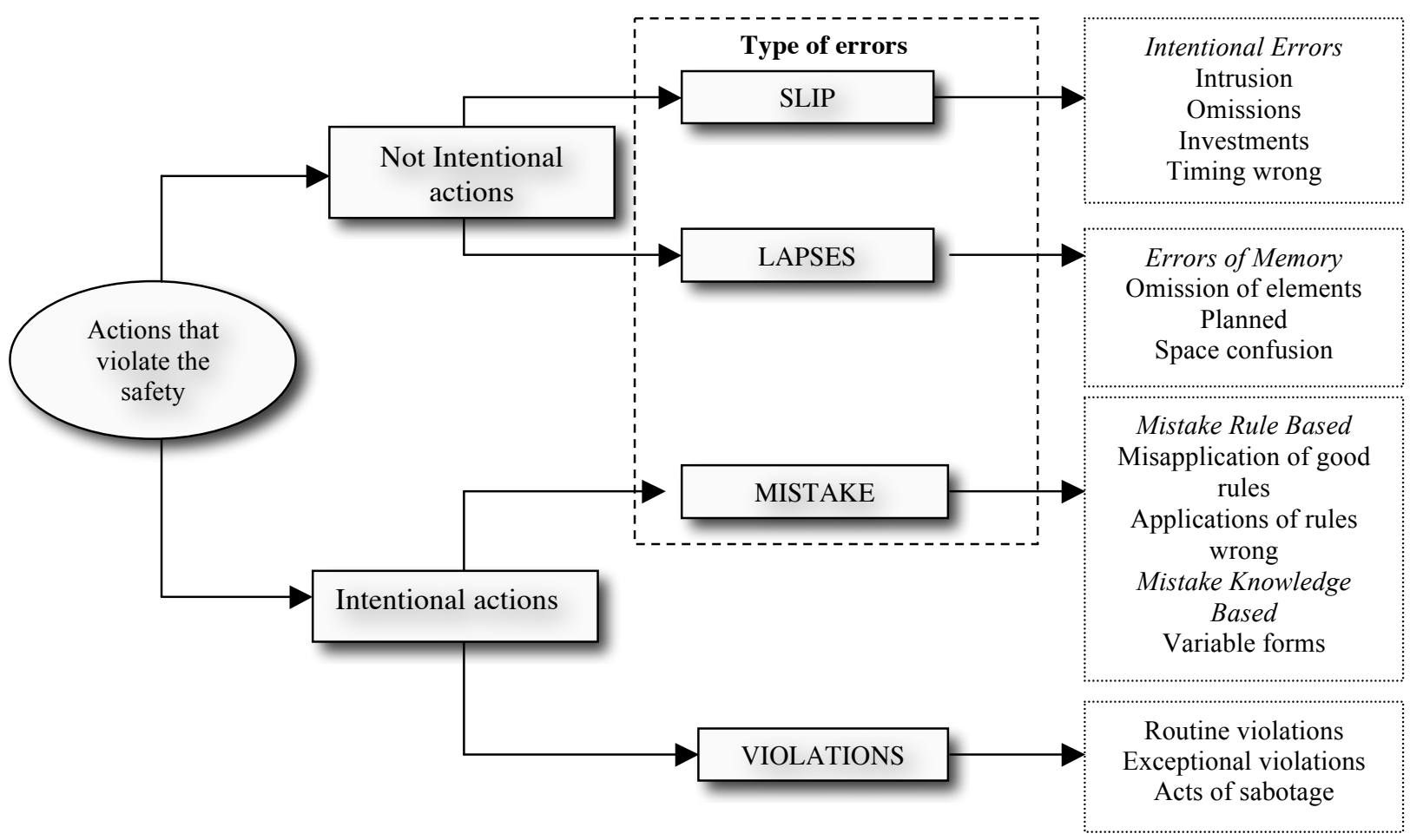

Figure 5. Actions that violate safety. 


\section{Model development}

At this point, taking advantage of the support of a group of safety experts and analyzing the problems of an automotive company, we have developed the ANP considering 5 macro clusters:

- Alternative;

- Technical errors;

- Human errors;

- Types of hazards;

- Consequences.

The model was developed considering the division "workshop" of the company.

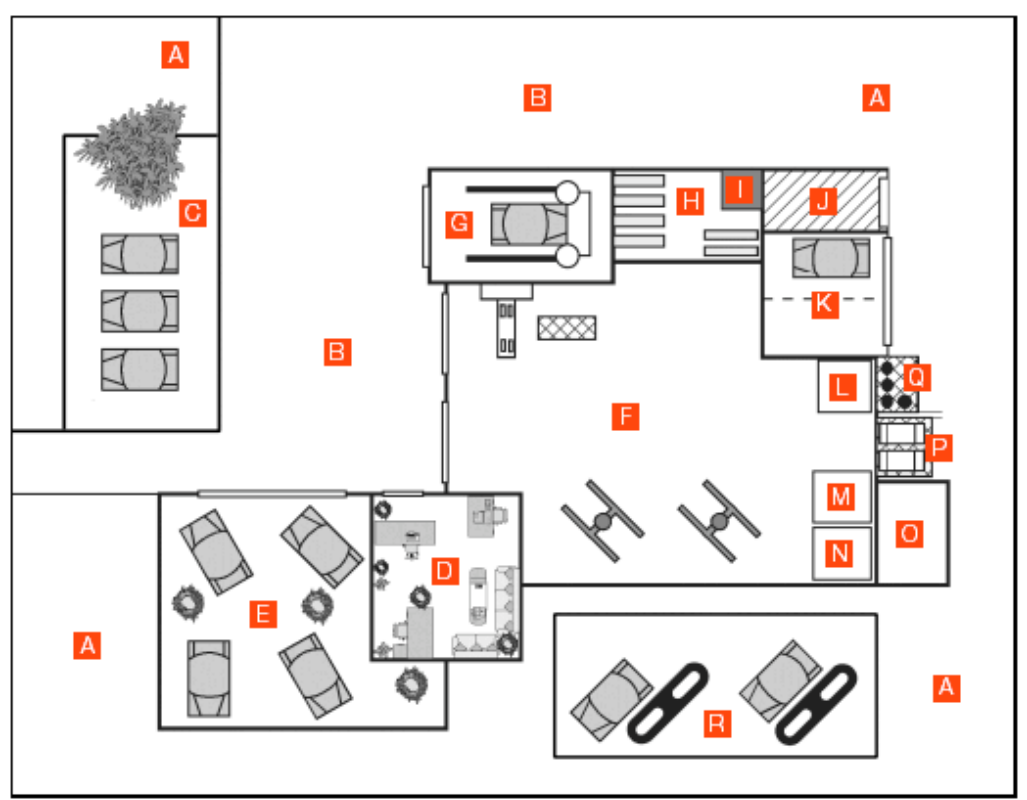

\begin{tabular}{|l|}
\hline Areas of work \\
A: Perimeter \\
B: Ramps for access and exit \\
C: Parking \\
Q: Reception, Offices, \\
Administration \\
E: Exhibition \\
F: Workshop \\
G: Car plant \\
H: Warehouse \\
I: Hazardous substances storage \\
J: Cabin painting \\
K: Department lactones, bodywork \\
L: Local storage and charger \\
M: Local compressors \\
N: Heating and ventilation \\
O: Workshop apprentices \\
P: Old containers and scrap metal \\
Q: Storage oils \\
R: Gas station
\end{tabular}

Figure 6. Example of workplace.

Now for the specific job category (Director) we have identified the work processes (activities) that characterize a typical workday, the work done, work equipment used, materials used, the main factors of hazard and stress (see tables below).

Table 2. Example detection activities/hazards/measures.

\begin{tabular}{|l|l|l|l|}
\hline Division: Workshop & Director \\
\hline Activity/equipment & Hazards & Support & Actions \\
\hline Lifting. & $\begin{array}{l}\text { Falling car. } \\
\text { Breaking carrier. }\end{array}$ & Checklist. & $\begin{array}{l}\text { Implement safety } \\
\text { measures. } \\
\text { Use checklist. }\end{array}$ \\
\hline Inserting battery car. & $\begin{array}{l}\text { Corrosives. } \\
\text { Explosion hazard. } \\
\text { Hazard burns. } \\
\text { Posture incongruous }\end{array}$ & $\begin{array}{l}\text { Safety specifications. } \\
\text { Checklist. }\end{array}$ & $\begin{array}{l}\text { Ban on Smoking. } \\
\text { Training on electrical } \\
\text { hazards, etc. }\end{array}$ \\
\hline
\end{tabular}




\begin{tabular}{|l|l|l|l|}
\hline $\begin{array}{l}\text { Fitting in brake pads } \\
\text { (containing asbestos) }\end{array}$ & $\begin{array}{l}\text { Hazard asbestos } \\
\text { exposure }\end{array}$ & $\begin{array}{l}\text { Ask intervention } \\
\text { hygienist employment }\end{array}$ \\
\hline
\end{tabular}

Table 3. Example identifying the causes of major hazards and stress factors.

\begin{tabular}{|c|c|c|c|}
\hline & Hazards & & Example \\
\hline 1 & $\begin{array}{l}\text { Mechanical Hazards. } \\
\text { Hazards of heat. }\end{array}$ & $\begin{array}{l}\text { Falling objects. } \\
\text { Materials or substances under } \\
\text { pressure. } \\
\text { Uncontrolled movement of } \\
\text { elements. } \\
\text { Hazardous parts with surface. }\end{array}$ & $\begin{array}{l}\text { Points of crushing, shearing, } \\
\text { impact, cut, puncture, drag, } \\
\text { entanglement corners, edges, } \\
\text { tips, cutting parts, roughness } \\
\text { points of collision/collision, } \\
\text { overturning. }\end{array}$ \\
\hline 2 & Hazards of falling. & $\begin{array}{l}\text { Working height openings in the } \\
\text { ground gradients. } \\
\text { Slippery surfaces. } \\
\text { Cable clutter on the floor } \\
\text { Visibility. }\end{array}$ & $\begin{array}{l}\text { Stairs, ramps, lifting, cables on } \\
\text { the floor, fog smoke. }\end{array}$ \\
\hline 3 & Electrical Hazards. & $\begin{array}{l}\text { Elements in voltage. } \\
\text { Electrostatic processes. } \\
\text { Short circuits, overloads, electric } \\
\text { arcs. }\end{array}$ & \\
\hline 4 & Psychological stress. & $\begin{array}{l}\text { Mental overload. } \\
\text { Repetitive Activities } \\
\text { Margin of work and decisions are } \\
\text { narrow. } \\
\text { Oppressive social conditions. } \\
\text { Too emotional with customers. }\end{array}$ & $\begin{array}{l}\text { Tight deadlines, too much } \\
\text { responsibility, routine tasks } \\
\text { without work reasoning, work } \\
\text { at the assembly too narrow } \\
\text { demands of customers } \\
\text { colleagues, superiors } \\
\text { discrimination, mobbing. }\end{array}$ \\
\hline 5 & $\begin{array}{l}\text { Biological and chemical } \\
\text { Substances. }\end{array}$ & Gas, vapor, liquid, solid. & $\begin{array}{l}\text { Toxic, carcinogenic, mutagenic, } \\
\text { irritating, corrosive, sensitizing } \\
\text { or toxic substances. }\end{array}$ \\
\hline 6 & $\begin{array}{l}\text { Hazards of fire and } \\
\text { explosion. }\end{array}$ & $\begin{array}{l}\text { Liquids, dust, gas, solids. } \\
\text { Explosive atmosphere, explosive } \\
\text { substances, sources of ignition. }\end{array}$ & $\begin{array}{l}\text { Solvents, gas liquids, } \\
\text { flammable solids, oxidising } \\
\text { substances. }\end{array}$ \\
\hline 7 & Particular physical stress. & $\begin{array}{l}\text { Noise, ultrasound, infrasound, } \\
\text { non-ionizing and ionizing } \\
\text { radiation. }\end{array}$ & $\begin{array}{l}\text { Continuous noise, impulsive } \\
\text { noise, ultrasonic/infrasound } \\
\text { noise transmitted by air or by } \\
\text { solid, alternating } \\
\text { electromagnetic fields (high and } \\
\text { low frequency). }\end{array}$ \\
\hline 8 & Work organization. & $\begin{array}{l}\text { Insufficient or inadequate skills. } \\
\text { Information / instructions } \\
\text { insufficient. } \\
\text { Frequent } \\
\text { distractions/interruptions. } \\
\text { Responsibilities unclear. } \\
\text { No feedback. } \\
\text { No involvement of employees. }\end{array}$ & $\begin{array}{l}\text { Documentation of work } \\
\text { instructions and non-existent or } \\
\text { inadequate information, } \\
\text { language barriers quality } \\
\text { controls only external shift } \\
\text { work/night working time } \\
\text { variable in the short term and } \\
\text { irregular. }\end{array}$ \\
\hline
\end{tabular}


Each cluster is characterized by sub-elements that allow us to identify with precision the object of our study or identify the various forms of error (genotypes), regardless of the erroneous actions that may be made (phenotypes), then we must identify what factors monitor in order to decrease the risks due to human error.

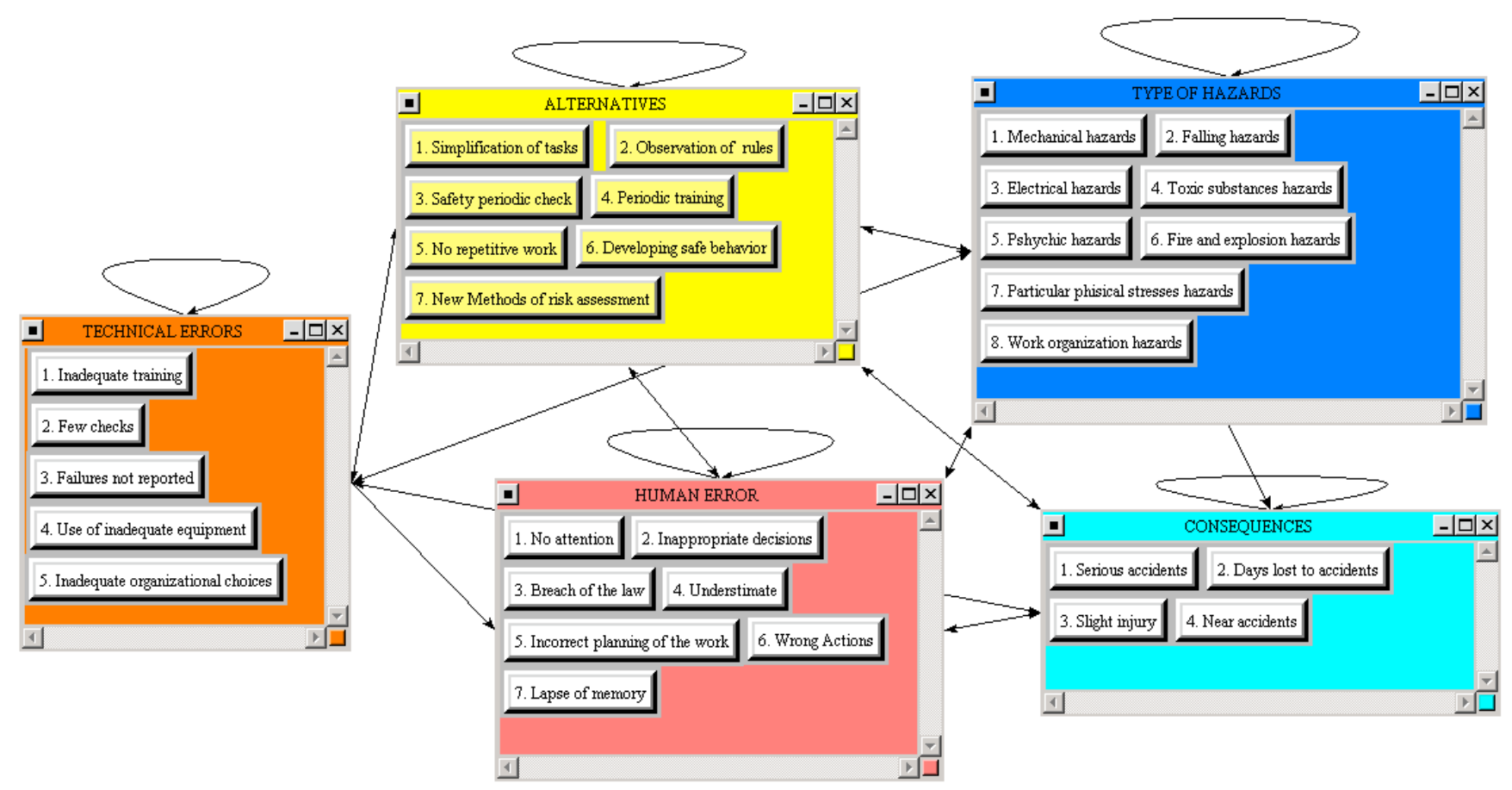

Figure 7. ANP Model.

The ANP model not only produces the priorities based on the reviews, but acts, as a measure to calculate the inherent contradiction of judicial decisions. This measure is useful in identifying potential errors that are being made in formulating the assessments, as well as contradictions in the actual assessments themselves.

The network developed allows us to identify the priorities for action.

We have a large number of comparisons. In this way we obtained a better classification. In particular, as we can see from the results the alternative to which we must act is "Develop safe behaviour" that is in order to optimize the management of safety at work it is necessary to implement an approach based on the BBS or we must work on better behavior to get better results. 

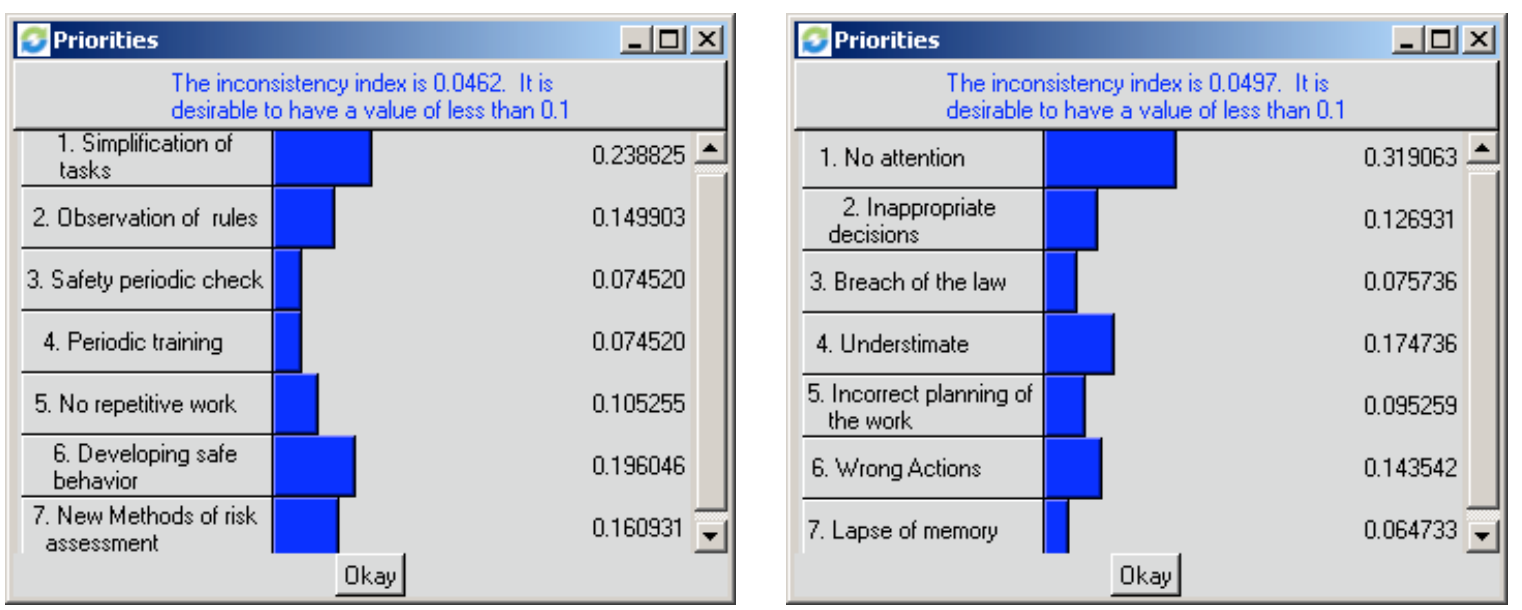

Figure 8. Priority vector for node "Simplification tasks" in Alternatives cluster and for node "Developing behavior safety" in Human Error Cluster.

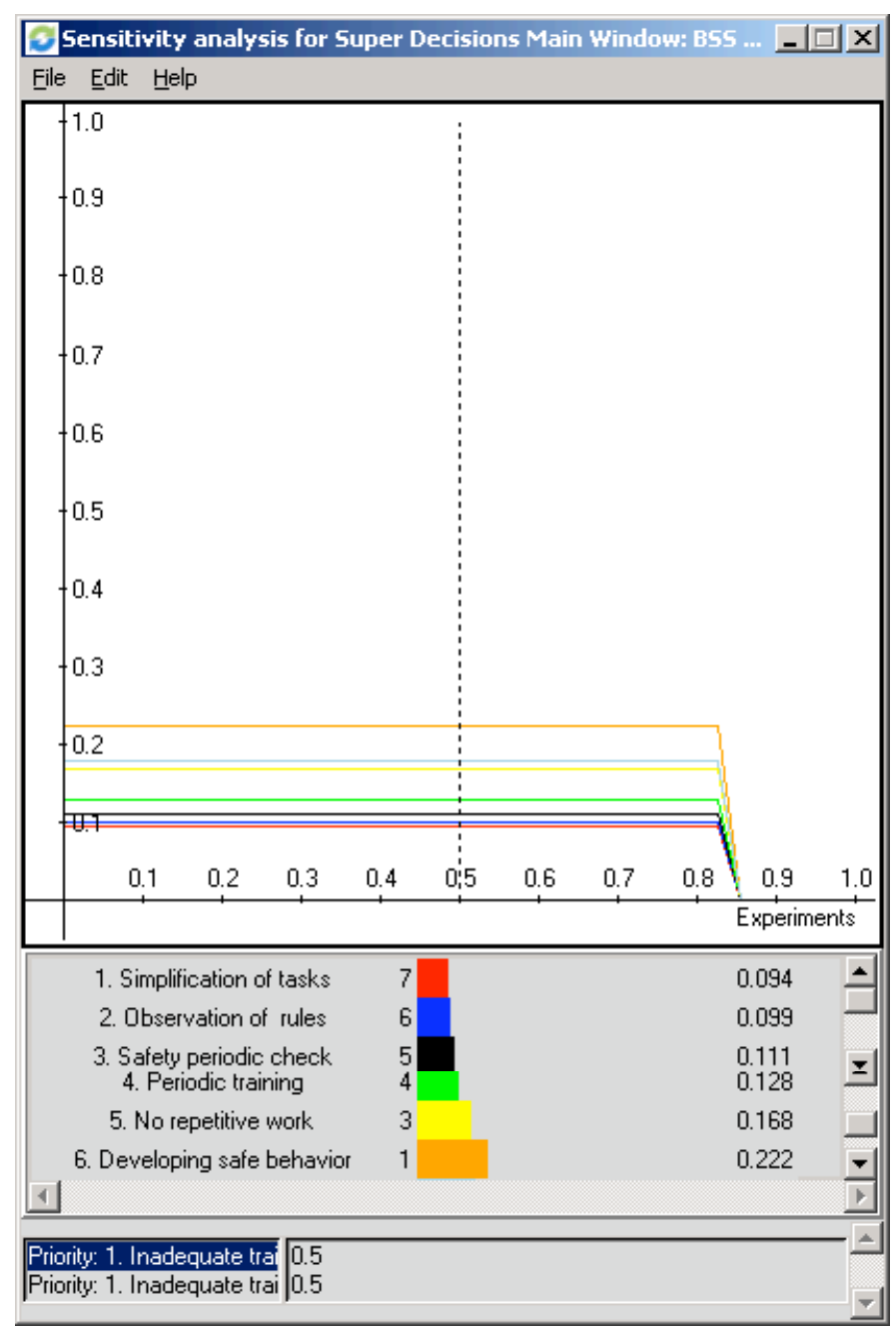

Figure 9. The Sensitivity Graph. 


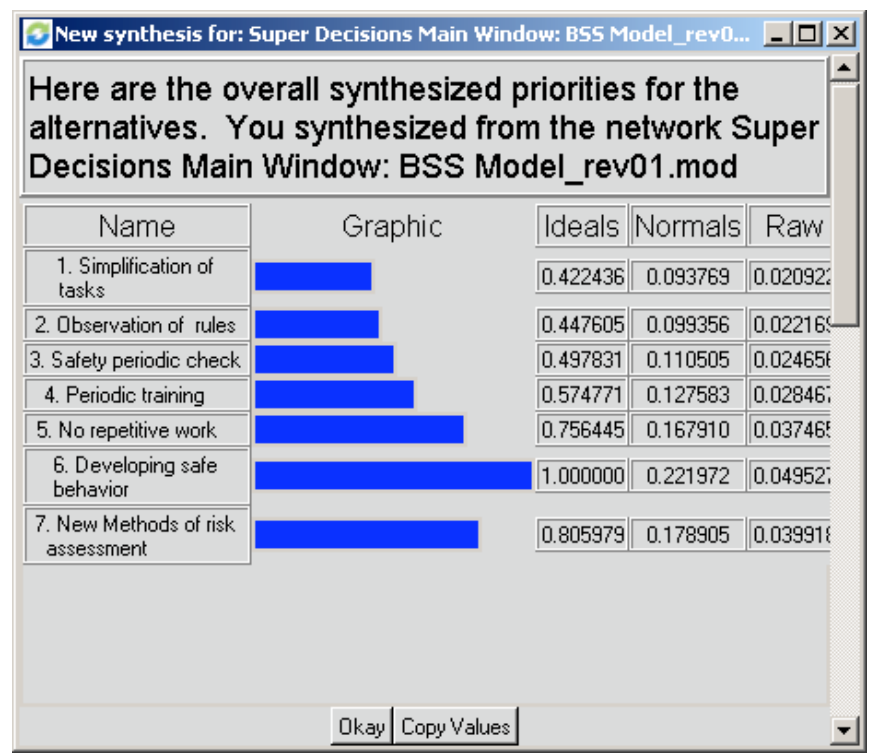

Figure 10. Synthesis of priorities.

Established priorities of action is necessary to implement the programs implementation. We propose as an example a simple program (we show only a partial implementation) for Process Safety based BBS.

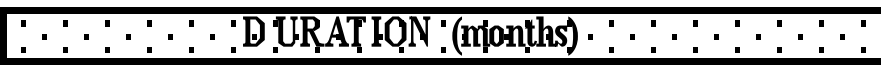

\begin{tabular}{|c|c|c|c|c|c|c|c|c|c|c|}
\hline$\because \because \because \because \because \because \because \because$ Activity $\because \because \because \because \because \because \because$ & \multicolumn{3}{|c|}{1 Quarter } & \multicolumn{3}{|c|}{2 Quarter } & \multicolumn{3}{|c|}{3 Quarter } & \\
\hline 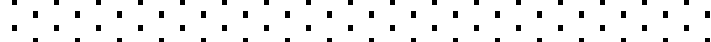 & Jan & $\mathrm{Feb}$ & Mar & Apr & May & Jun & July & Aug & Sept & \\
\hline Development process observation & & & & & & & & & & \\
\hline Definition feedback andiwwolvement & & & & & & & & & & \\
\hline Implementation of the sistem of awards for safety & & & & & & & & & & \\
\hline Administration of traiming support & & & & & & & & & & \\
\hline Assessment of the safety & & & & & & & & & & \\
\hline Implementation of the pilot site & & & & & & & & & & \\
\hline Training of site safety team & & & & & & & & & & \\
\hline
\end{tabular}

Figure 11. Example about Program for BBS.

The model developed reduces the degree of arbitrariness of the evaluation process through two key features:

- The estimation is carried out through a network that allows a comparison between different clusters;

- The estimates do not take place through point values, but distributions of values.

Obviously, to obtain a safety based on the types of success:

- There are no absolute guidelines, all that is implemented must provide for the organization and the general guidelines should be reviewed authorize from time to time;

- The observation process takes time, and requires active support at all levels of management. 


\section{Conclusions}

In conclusion we can say that for the safety of workers, give priority to prevention strategies should be given, compared to the protection maneuvers from the consequences of error. It is quite evident that the role attributed to the reliability of the human factor in modern production processes should reach a level equal to that of mechanical components in the respect to the technological one man - machine system the reliability of humans was for a long time neglected. From what we have just mentioned and that human error in any field can not be eliminated but only controlled, we are witnessing a development of multi criteria techniques such as ANP that are able to provide valuable support in risk management. The main feature of this methodology is that it facilitates the integration of objective and subjective evaluations, qualitative and quantitative and can use the broad spectrum of information available. Another key feature is the expressing of opinions which give us a good correspondence with the human mental categories. In order to analyse the problem of safety in a "human" prospective a continuous and increased distribution of such methodologies is necessary. There is thus a more global view of the problem, in which a complex system can be seen as an organization with various levels of "protection" from error. Each level, however, has its internal weaknesses. Therefore, greater efforts must be directed at minimizing the generation of latent errors, active since error is difficult to eradicate. It is essential to have methods to allow the generalization of the model in order to secure applications in different fields, and the standardization of the method to ensure easy application and integration applicable to one or more areas of operational safety by allowing to perform retrospective and prospective analysis at the same time, because only through proactive investigations of qualitative and quantitative types we can analyze the process in its various stages, identify the criticality of the system, the possible areas of human error and immediately find the solution.

\section{REFERENCES}

Albayrak E., Erensal Y., C. (2004). Using analytic hierarchy process (AHP) to improve human performance: An application of multiple criteria decision making. Journal of Intelligent Manufacturing.

Better Than Conscious?: Decision Making, the Human Mind, and Implications for Institutions, (2008). MIT Press.

Carpignano A., Piccini M. (1999). Cognitive Theories and Engineering Approaches for Safety Assessment and Design of automated systems: A Case Study of a Power Plant. Cognition, Technology \& Work, 1:47-61 Springer-Verlag London Limited.

Cho C. W. (2005). The Knowing Organization: How Organizations Use Information to Construct Meaning, Create Knowledge, and Make Decisions, Oxford University Press.

De Felice F., Falcone D., Di Bona G., Silvestri A. (2004). R.A.M.S. Analysis in a sintering plant by the employment of a new Reliability Allocation Method Modelling and Simulation 2004 Marina del Rey, CA, USA.

De Felice F., Falcone D., Silvestri A., Petrillo L. (2005). Proposal of a New Decision Making multi criteria Methodology applied to the reengineering of layout in an electromechanical company: the Score Analytic Hierarchy Process, $18^{\text {th }}$ International Conference on Production research, Salerno (Italy).

Hollnagel, R. (1998). Cognitive Reliability and error Analysis Method (CREAM). Elsevier. 
Humphreys P., Ayestaren S., McCosh A., Mayon-White B. (1997). Decision support in organizational transformation, Ed. Chapman \& Hall.

Kuo W., Rajendra Prasad V. (2006). Optimal Reliability Design: Fundamentals and Applications, Cambridge University Press.

Leskinen P. (2000). Measurement scales and scale independence in the Analytic Hierarchy Process, Journal of Multi-criteria decision Analysis.

McSween T., E., (1995). The Values-Based Safety Process : Improving Your Safety Culture with Behavior-Based Safety. John Wiley \& Sons Inc.

Reason J. (1997). Managing the Risks of Organizational Accidents. Ashgate Publishing, 1997.

Saaty, T.L. (2005). Theory and Applications of the Analytic network Process: decision making with benefits, opportunities, costs, and risks, Ed. RWS Publications.

Saaty T. L. (2006). Fundamentals of decision making and priority theory with the Analytic Hierarchy process, Ed. RWS Publications.

Saaty T. L. (2000). The Analytic Hierarchy Process, McGraw-Hill. 